\title{
An integrative approach to the Marfan aortic root between the patient, the physician and basic scientists: A case study in personalised external aortic root support (PEARS)
}

\author{
Tal Golesworthy ${ }^{1}$, Peter Verbrugghe ${ }^{2}$, Cemil Izgi ${ }^{3}$, Shelly Singh ${ }^{4}$ and Tom Treasure ${ }^{5 *}$ \\ ${ }^{1}$ Exstent Ltd, Tewkesbury, UK \\ ${ }^{2}$ Department of Cardiac Surgery, UZ Leuven, Herestraat 49, 3000 Leuven, Belgium \\ ${ }^{3}$ Cardiovascular Magnetic Resonance Unit, Royal Brompton Hospital, London, UK \\ ${ }^{4}$ Department of Chemical Engineering, Imperial College, London, UK \\ ${ }^{5}$ Clinical Operational Research Unit, University College London, London, UK
}

\begin{abstract}
Aortic root aneurysm is a characteristic feature of Marfan syndrome and is the commonest cause of death in the natural history of this condition. Aortic root replacement, introduced in the 1960s and iteratively developed over the subsequent thirty years dramatically improved the prognosis for people with Marfan syndrome. In 2004 a fundamentally different approach was introduced. Rather than surgical resection of the fibrillin deficient aorta, and its replacement with a fabric tube graft, an external support, custom made to the shape and size of the individual's aortic root, was manufactured in preparation for surgery. At operation this is positioned around the aorta extending proximally to the aorto-ventricular junction and distally to beyond the origin of the brachiocephalic artery. This operation has now been done in over 65 patients, mostly with Marfan syndrome, with 270 patient/years of follow-up. The mesh is soft, pliable and macroporous. Histologically the mesh can be seen to become incorporated in the aortic adventitia with collagen fibres passing through its interstices to form a strong composite neo-aorta without sacrificing the natural blood/endothelial interface and maintaining the natural support of the aortic valve within the sinuses of Valsalva. In this article we concentrate on the collaborations between disciplines which have allowed the development and further investigation of this method. All conclusions at this stage are tentative because the follow-up is not long enough to be fully confidant of the results. At present the best indication for PEARS is early in the progression of the root aneurysm when it offers conservation of the aortic valve and the blood/endothelial interface with the hope of indefinitely minimising the hazards of the aortic root.
\end{abstract}

\section{The clinical problem}

'The signature manifestation of cardiovascular pathology in MFS is a grossly dilated aortic root, which commonly results in aneurysm, aortic valve regurgitation, and an increased risk of dissection, rupture, and death; hence, the root is the source of all evil affecting patients with MFS' [1].

This stark summary from one of the USA's leading surgeons specialising in aortic disease is a fair introduction to the problem.

\section{The 'natural history'}

The expectation of life for people with Marfan people is severely reduced by the prospect of aortic dissection. The landmark study came from Johns Hopkins in Baltimore, USA and it remains our best estimate of the natural history of the disease. In their dataset were 257 patients with Marfan syndrome. Half of the men had died by their late thirties and the average age of death for women was about ten years later. The average age at death was 32 years and where the cause was known it was overwhelmingly the result of aortic root dissection [2]. A more sophisticated study of natural history will never be possible because now, at the first suspicion of Marfan syndrome, the aortic root can be measured non-invasively by echocardiography. This was undreamt of at the time the Johns Hopkins authors were accumulating their data. However, there is no reason to revisit it: the main thrust of their evidence in incontrovertible (Figure 1).
People with Marfan syndrome still die of aortic dissection and many of these deaths should now be avoidable (Figure 1 and 2). The underlying problem is deficiency of fibrillin- 1 which is both a structural protein and a regulator of the transforming growth factor $\beta$ (TGF- $\beta$ ) signalling pathway. Clinical trials of medical treatment intended to stabilise the fibrillindeficient aorta of Marfan syndrome have so far failed to show the clinical benefit which was hoped for based on experiments in mice [3]. There can be little room for doubt that surgery to prevent dissection of the aortic root remains for now the single biggest contribution to the greatly increased expectation of life for people with Marfan syndrome who can now expect to live on average into their seventies. Until the central problem of genetically determined fibrillin deficiency can be solved, prophylactic surgery is the mainstay for treatment and more than doubles their average life expectancy from fewer than four decades to more than seven decades (Figure 2).

\section{The first fix}

Bentall's case report from 1968 is universally accepted as the 'first

Correspondence to: Tom Treasure, Clinical Operational Research Unit, University College London, London UK, E-mail: tom.treasure@gmail.com

Key words: aortic root aneurysm, Marfan syndrome, external support

Received: May 02, 2016; Accepted: May 21, 2016; Published: May 24, 2016 

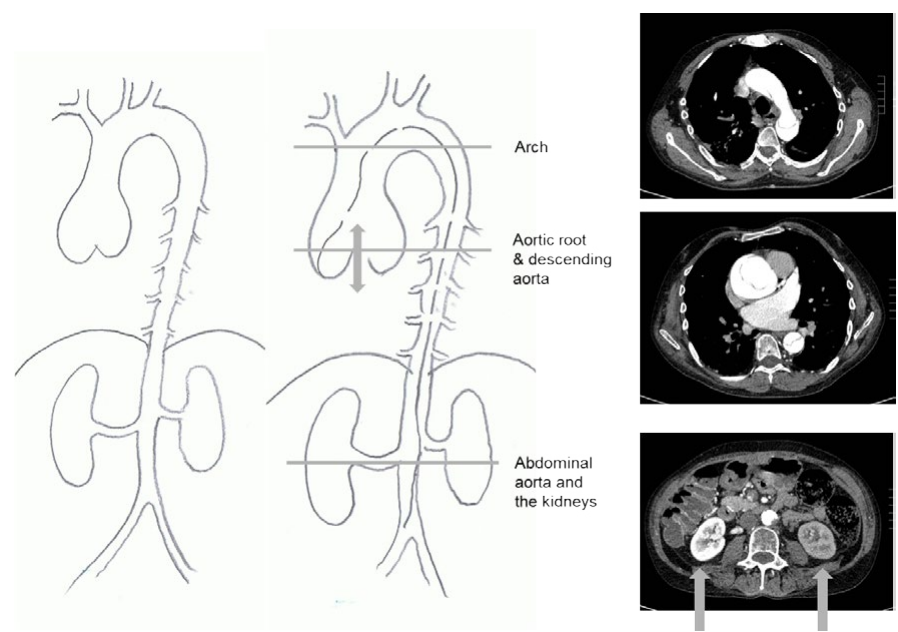

Figure 1. Computed tomography images and explanatory surgeon's drawing of a Type A aortic dissection in a patient with typical Marfan syndrome from a family with numerous affected members. The dissection has halted flow to the left kidney which is not functioning. The dissection proved fatal.

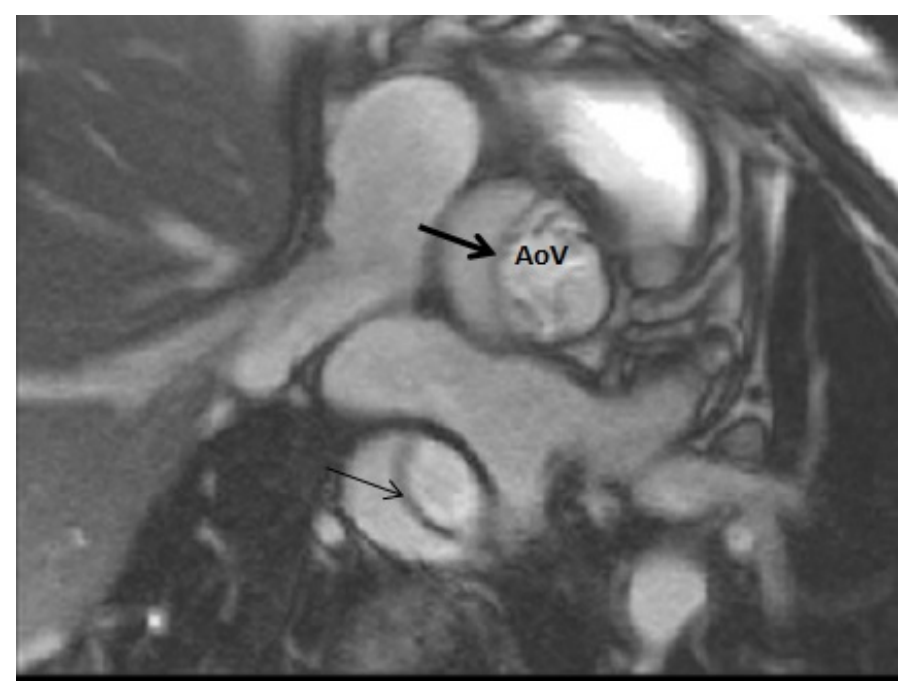

Figure 2. Cardiac magnetic resonance image of a typical Type A dissection.

composite replacement of the ascending aorta and the aortic valve [4]. Surgical replacement of the ascending aorta for aneurysm was a considerable challenge at the time and when it had been done, the proximal anastomosis was made distal to the coronary orifices [5]. There had been cases of replacement of the aneurysmal aorta and the valve but that left the sinuses of Valsalva, the most vulnerable part of the aorta, still there to present a hazard. Replacement of the aorta and valve together and reattaching the coronary arteries was Bentall's breakthrough.

\section{The iterative improvements to reach 'the modern Bentall'}

After Bentall's publication, root replacement slowly became established it but remained a challenging operation. It was unmentioned in the Johns Hopkins paper four years later in 1972 and until the 1980s it was an operation only performed in relatively few centres and then only when the aorta was at threatening size. The first PEARS operation was in 2004 and while there have been more than 60 operations performed it too has passed unremarked twelve years later in the most recent publication from Johns Hopkins [6] while valve sparing root replacement has become the more frequently performed operation rather than the modern Bentall. Surgeons are understandable reluctant to embark on new and potentially hazardous operations but we know that there is a risk for the patient if surgeons are prevented from taking risks in a risk averse society [7].

In the present article we reflect in the integrative research work undertaken to reach the point where aortic root surgery is now [8]. The undesirable aspects of the original Bentall operation were overcome stepwise. The original tube grafts had to be preclotted; successive introduction of collagen and gelatine sealed grafts overcame that problem. Surgeons initially had to hand sew the valve into the tube but later manufacturers provided surgeons with factory made valved conduits. The coronary anastomoses were for a time the Achilles' heel of the operation. The ostia were originally sutured en face into the tube graft and the aorta wrapped around the graft but perigraft leaks and pseudoaneurysm formation were a familiar problem. With surgical skill and practice a button technique, in which the coronaries were directly anastomosed to the tube graft, largely overcame those problems.

\section{Valve sparing root replacement}

The next great step was valve sparing root replacement. Some surgeons were concerned that the valve leaflets would also prove to be involved with the degenerative disease. Valve sparing versions of the operation were separately developed by Yacoub [9] and David [10] and the valve leaflets proved to be durable. When they failed it was not leaflet tissue failure that was the problem. More often it was continued dilatation of the root or other factors related to the architecture of the root and the support of the aortic valve. Time has shown that of the two, David's approach has been less prone to this mode of failure and is now generally preferred.

The opportunity to conserve the patient's aortic valve and avoid life-long anticoagulation encouraged intervention earlier in the progression of aortic root aneurysm formation, while the valve could be more predictably and successfully conserved. The risk of dissection is related to the size of the aorta and to its rate of change in size. In recommending surgery other factors are taken into account such as aortic valve regurgitation or an ominous family history which would prompt earlier intervention. As root replacement could be performed with progressively lower risk, there was progressive reduction in the threshold size at which a patient's risk of dying with even a relative small aneurysm exceeded the risks of surgery [11]. In 1993 the suggested threshold for recommending root replacement in Marfan syndrome was $5.5 \mathrm{~cm}$ [12]. By 2000 it was $5.0 \mathrm{~cm}$ and consensus guidelines in Europe and America now recommend $4.5 \mathrm{~cm}[13,14]$. However this is still major surgery and there are perioperative and ongoing risks. The biggest concern with valve sparing surgery is later onset and progression of aortic valve regurgitation resulting in further surgery at a rate of about $13 \%$ per decade. On the other hand, root replacement with a mechanical valve is associated with $7 \%$ thromboembolic risk per decade [15].

\section{A new way of thinking}

One of the present authors (TG) and engineer in research and development faced having a composite aortic root graft and consequent life-long warfarin anti-coagulation. It was actually the fear of permanent anti-coagulation that drove him to think of another way [16]. He was reconciled to the need for surgery but could not see why his aorta and working valve had to be removed. His question was why 
not used modern methods of design and prototype manufacture to create an external support?

\section{Research before "the first in man"operation CAD modelling and making a rapid prototype}

For each patient, measurements derived from MRI or CT images are processed using a dedicated computer aided design (CAD) routine, specifically designed to model the ascending aorta, to produce a $3 \mathrm{D}$ reconstruction of the individual patient's aorta [17]. Initially MRI was used particularly because we anticipated the need to do repeated imaging of the aortic root to monitor the shape and size of the root. Later we have increasingly used CT (Figure 3).

One important lesson learned in the context of integrative medical research was the revelation that medicine had fundamentally broken the convention in displaying images. Plans and architects' drawings are always set up so that the view point is above. That is true even for roofers. The earliest images of the heart were its silhouette on chest radiographs. These are viewed as if facing the patient with the right side of the patient's image to the doctor's left, matching the view of the patient in front of her. When cross sectional images became available for reasons of the convention of the 'anatomical position' the spine was downward and this was appropriate as the images were made with the patient is lying supine. A convention emerged that they too would be viewed with the patient's right to the doctor's left. This has the result the cross-sectional images are viewed as if from below opposite to other plan views. The first reconstructions were brought to a clinician to review (TT). The aorta was seen as a 3-D reconstruction on a computer screen. Of particular importance to the engineer was confirmation of the correct siting of the coronary attachments. Rotating the image clockwise and anticlockwise the image on the screen did not make sense. Suddenly the explanation dawned. The engineer had reconstructed the images in the convention of plan views intended to be looked at as if from above and had thus created a vertical mirror image of the aorta [18]. This led to an important and generalizable lesson. In integrative research it is vital to take nothing for granted and to ensure that we take time to explain and listen to each other with particular respect to discipline-specific nomenclature,

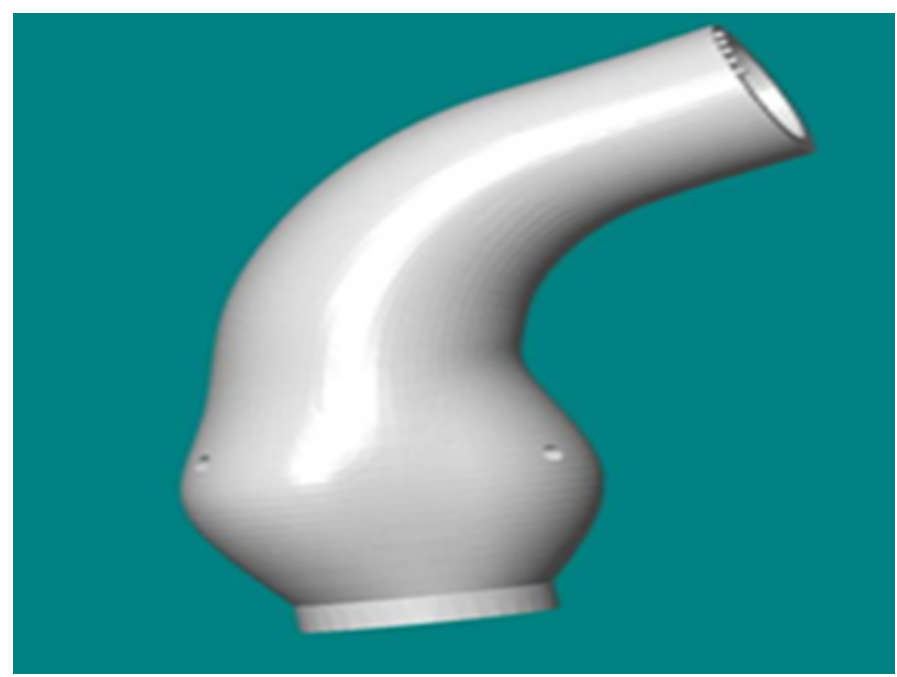

Figure 3. A computer aided design (CAD) model viewed on the screen. The orifices of the pulmonary artery are marked. Viewed as if from the patients left the right coronary arises at the front of the aorta and the left coronary orifice to the rear. The 'left' in this nomenclature is because the artery supplies predominately the 'left' ventricle which is in turn is named more for reasons of physiological right/left heart conventions than that it is leftward. measurement and embedded conventions. It was said to be a failure to recognise different measurement conventions that led to the crash of NASA’s \$125-million Mars Climate Orbiter in 1999.

\section{The chemical properties and biological interface issues}

Vascular grafts have been made for well over fifty years from a polymer PolyEthylene Terephthalate (PET). It has good biocompatibility. It is made into fabrics/textiles of various kinds for use in surgery. The familiar vascular grafts are made in a low porosity weave so that the interstices will quickly seal as coagulability is restored when heparin is reversed. It is also useful if they have some wall stiffness so that they will follow a curve with a low tendency to kink. However this produces stiff material with abrasive edges. Surgeons who devised means of 'wrapping' the aorta used the material to hand and it was these vascular graft textiles that were used [19-21] (Figure 4).

One disadvantage of using vascular grafts in this way, and one repeatedly brought to our attention, is that there are reported instances of wraps 'migrating' [22]. As the material shifts its abrasive edge can injure delicate structures and particularly the nearby coronary arteries. The macro physical properties required of an external support textile for the aorta are significantly different from the conventional stiff, woven grafts then available.

The fabric used for external support, (ExoVasc PEARS implant, Exstent Ltd, Tewkesbury, UK) while being the same polymer and similar biocompatability is knitted and much less dense. It is very soft and presents no edge. It is also porous with interstices of $0.7 \mathrm{~mm}$. This would be fatal if used to replace an arterial wall because the patient would bleed to death in minutes but haemostasis is not required of the fabric in the PEARS operation. The blood is still contained within the patient's own aortic wall with its healthy and normal endothelium providing a kindly interface with the blood (Figure 5-8).

\section{First in man}

On $24^{\text {th }}$ May 2004 the first operation was performed and the first recipient was the inventor himself [23]. The operation was carefully worked out and there has been not revision of the essential features of

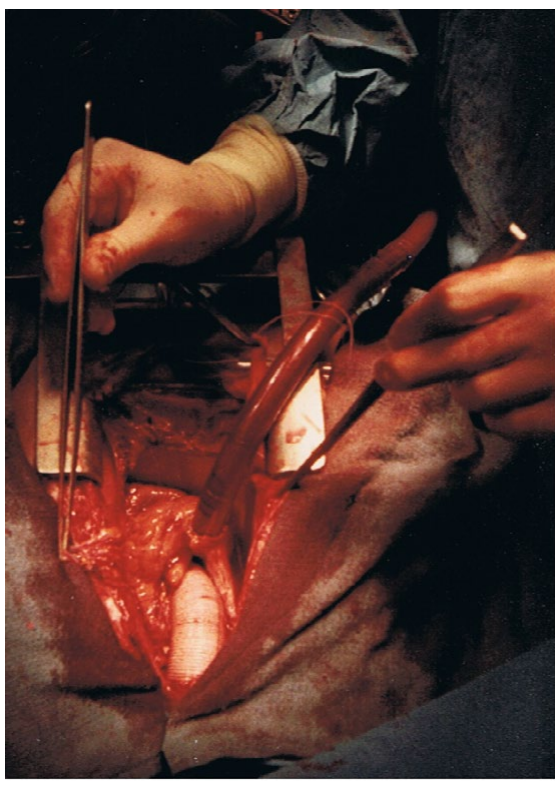

Figure 4. A completed ascending aortic replacement. 1985. 


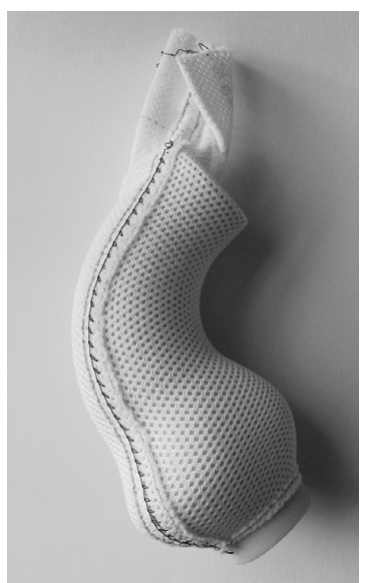

Figure 5. The shape is provided by the rigid former. The mesh itself is soft, pliable and with no stiffness or hard edges as can be seen beyond the extent of the former. The seam up the front is released and re-sutured once the mesh is positioned around the aorta.

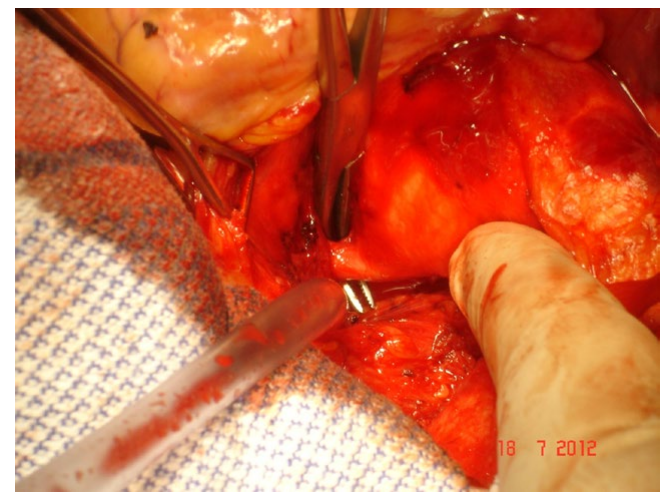

Figure 6. A tense moment as the dissector is passed proximal to the left coronary artery.

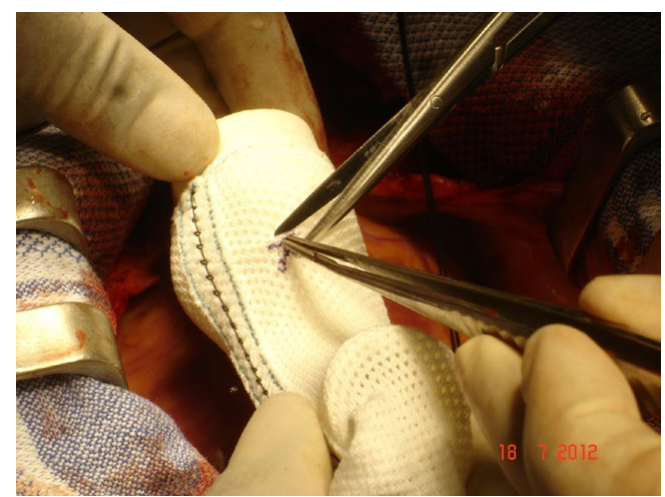

Figure 7. An incision will be made from the longitudinal seam but the opening for the coronary artery itself is an asterisk configuration so that no edge is presented directly to the coronary artery.

the method although there have been refinements with experience. The external support was brought to the operating table on its former which is an exact model of the patient's own aorta and the orientation can be visually confirmed (Figure 5). Fine right angle forceps are useful for dissecting "under" the coronary arteries (Figure 6). Control of arterial pressure is vital especially when dissecting between the aorta and right ventricular outflow tract. After careful confirmation of the orientation, the openings for the coronary arteries are made in the support mesh (Figure 7). These are made in the form of asterisks so that no one edge impinges in the coronary artery but the tongues can extend onto its external surface offering an opportunity to be tethered there by the healing process. The longitudinal seam, which is anterior and runs down the non-coronary sinus, is opened. The transverse extensions from the axial seam to the coronary openings are made. The tongues of mesh material which are thus created are passed proximal to (beneath) the coronary arteries and the incisions in the mesh extending to the coronary orifices are then sutured. The lower margin of the support is secured to the aorta-ventricular junction. The anterior seam is sutured. With the arterial pressure low, the mesh is loose around the aorta but as the pressure is allowed to normalise the aorta expands and puts the supporting mesh under tension (Figure 8).

\section{Research after $1^{\text {st }}$ in man}

The first operation was in the inventor. Why not an animal? It is in fact unusual for operations to be rehearsed in animals before being applied in man, even though that might be a public perception. More often the first attempts are made, as here, in humans and if the operation looks as though it is worth pursuing, this prompts animal experiments to resolve biological questions. That may be surprising but is has very often been the case

\section{Biological incorporation}

There had been prior experience with this PET fabric but it had appeared with the word 'girdling' in the title [24]. This defeated our searches. We are at fault too for putting 'jacket' in our original title [23] and other subsequent reports have has used the words 'sleeve'[25] and 'corset' [26]. We now think that tricky and enigmatic titles are best avoided; they may defeat indexing and searching to no one's advantage. The 'girdling' paper by Cohen et al should have been known to us in the development phase but it was not and we had to discover the potential for incorporation for ourselves. Cohen et al present a histological image in their paper showing the mesh incorporated in the aortic adventitia with ingrowth of collagen (Figure 9).

Colleagues in Leuven undertook a series of survival experiments in sheep to address the uncertainties we had about the security of the external support and its effect on the histology of the blood vessel wall.

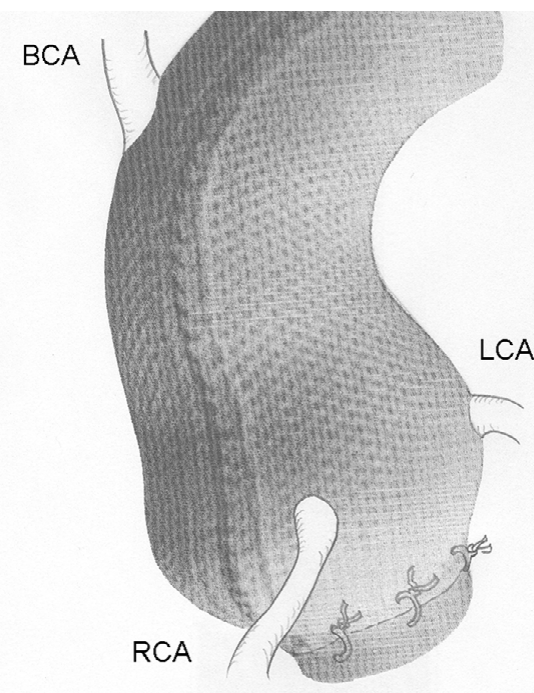

Figure 8. A schematic to show the eventual position of the mesh with respect to the brachiocephalic artery (BCA) and the left and right coronary arteries (RCA, LCA) and the tethering stitches to aortoventricular junction. The tethering is a temporary measure because the flask shaped nature of the mesh and the root will cause it to retain its position and it becomes adherent and eventually incorporated. 
The carotid arteries of growing sheep were enclosed in a sleeve of our support mesh. After 4-6 months the arteries were excised. There was an increase in the overall thickness of the arterial wall (Figure 9) [27]. This in contrast to the report of Neri et al in which the aortic wall underlying the reinforcement of a conventional woven graft was extremely thin with atrophy of the aorta [28]. Histological evaluation of the supported carotid arteries showed densely incorporation of the mesh in the adventitia, associated with a strong fibrotic reaction. This was reflected in a significant increase in maximum tensile strength of the supported segments compared to normal arterial tissue [27].This in itself would prevent aortic rupture, as this occurs when the wall stress exceeds the tensile strength of the aortic wall. This overall increasing in thickness of the aortic wall is discernible on the MRI images in the first patients after ten years (2004 to 2014) (Figures 10 and 11).

\section{Autopsy findings}

Only one patient has died with a mesh in place providing our only opportunity to see how the mesh behaves in the human Marfan aorta. This confirmed the previous observations that collagen fibres had grown through the interstices of the mesh (and between fibres in the threads/ yarns) and outside it making a tight integrated neo-aortic wall [29]. This was just as we had seen in the sheep and was as we hoped and perhaps expected. Not expected and remarkable was that there appeared to be

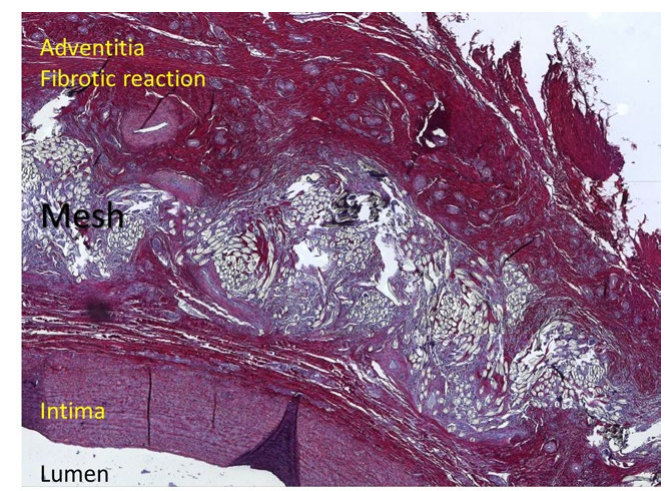

Figure 9. Sirius red staining of a carotid artery five months after being sleeved with mesh. It shows an intact vascular architecture with densely incorporated mesh material with a fibrotic reaction around it.
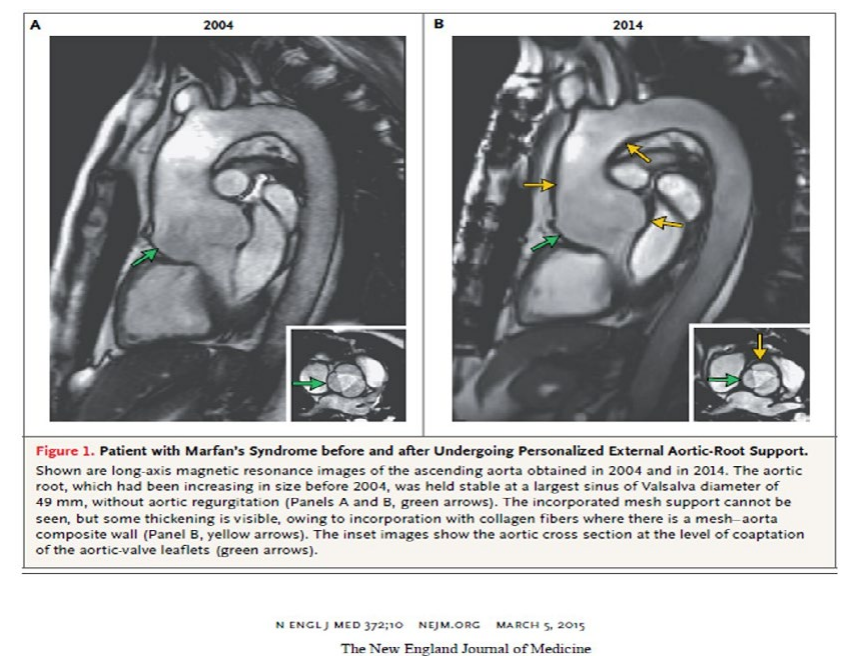

Figure 10. The cardiac magnetic resonance (CMR) images of the first patient (TG) before and then years after undergoing the first PEARS operation. healing of the media. Histological sections of the aorta from the arch, beyond the support, showed the characteristic appearance of medial degeneration. More proximally, where one would have expected the histology to be worse, with more degenerative changes, it was in fact normal with respect to the histological appearance. The most likely explanation is that the degeneration of the aortic media had healed. While we were surprised to see it, on reflection a standard tried and tested means of getting collagen to heal elsewhere is to splint it. That is how torn tendons are treated. Were we witnessing for the first time a beneficial effect on splinting on the aorta? (Figure 11).

\section{Proof of principle in terms of holding the sinuses and valve}

We studied the effect of external support in a rigorously conducted prospective study in the first ten patients operated on from 2004 to 2007. All patients had surgery as planned without complications and had completed at least one year of follow-up. MRI images before and after PEARS were presented for measurement amongst duplicate images of 37 unoperated Marfan patients to permit assessment of intraobserver measurement reproducibility. All 94 images were presented in random sequence to a radiologist unaware of the research question.
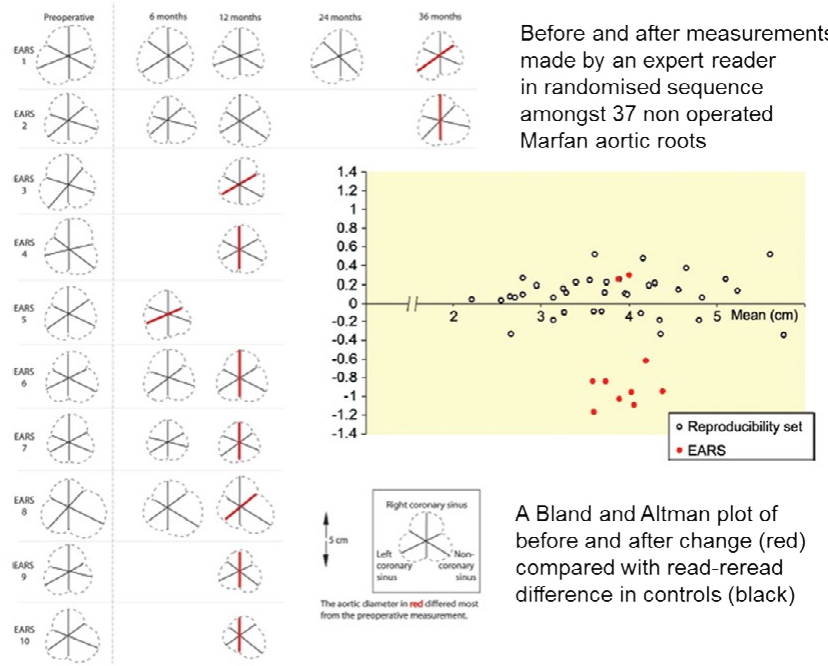

A Bland and Altman plot of before and after change (red) compared with read-reread difference in controls (black)

Figure 11. The cardiac magnetic resonance (CMR) images of the first patient (TG) before and then years after undergoing the first PEARS operation.

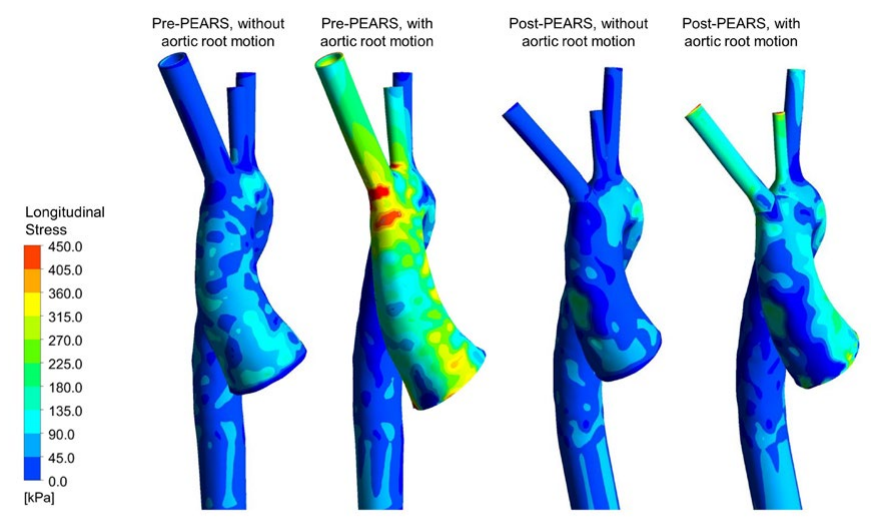

Figure 12. Longitudinal stress distributions in finite element models (with and withou aortic root motion) of a Marfan patient before and after PEARS implantation 
Measurements were made of the ascending aorta at the level of closure of the aortic valve cusps from magnetic resonance imaging studies taken preoperatively and at fixed intervals thereafter. The largest difference between the preoperative measurement and that made at least one year after surgery was determined. In eight of the ten patients, the largest observed change was a marked reduction in aortic root diameter. The primary objective of this surgery was achieved in each case, reinforcing the ascending aorta whilst leaving the native aortic valve intact and conserving the blood/endothelium interface (Figure 11).

The configuration of the aorta was unchanged and there were no instances of valve deterioration. The aortic root dimensions were generally smaller. This is because under operative conditions the aorta is under less tension and closure of the mesh holds it at a slightly smaller size which was an inadvertent but welcome effect.

\section{Means of comparison before it is possible to have a randomised trial}

We were prepared to subject PEARS to a randomised controlled trial and proposed this in journal articles and in meetings [30,31]. This was going to take time so first we started by doing a matching study using available data. Our hypothesis was that PEARS reduced the burden of care compared with aortic root replacement.

A matched comparison group, of similar age, aortic size and aortic valve function to those having the novel intervention, was constructed, by minimization [32] from among patients who had aortic root replacement during the same time frame. The first 20 patients, aged 16-58 years with aortic root diameters of $40-54 \mathrm{~mm}$, having external support surgery were compared with 20 patients, aged $18-63$ years and aortic root diameters of $38-58 \mathrm{~mm}$, who had conventional aortic root replacement, between May 2004 and December 2009.

Comparing total root replacement and customised aortic root support surgery, cardiopulmonary bypass (CPB) was used in only the first PEARS patient for 20 minutes compared with 134 minutes (range 52-316 minutes) for root replacement. There was no myocardial ischaemia for PEARS but a median of 114 minutes (41-250 minutes) for root replacement. There were similar large differences for blood loss and blood product usage which was rarely required for PEARS.

\section{Opportunities for explicative research}

\section{Aortic wall stress by MRI}

There was much theorizing as to whether supporting the ascending aorta might transfer the stress to other parts of the aorta. The critics largely avoided the fact that tube graft replacement had been practiced for fifty years and this was not a central problem. However we were accumulating a good number of patients and had the opportunity to study this question with magnetic resonance imaging. The aim of this study was to assess the mechanical effects of PEARS on aortic root systolic downward motion (an important determinant of aortic wall stress), aortic root distension and on the left ventricle (LV).

The cohort of 27 Marfan patients who had prophylactic PEARS surgery between 2004 and 2012 were included. Systolic downward aortic root motion and aortic root distension before the operation and in the latest follow-up were measured randomly and blindly after a median follow-up of 50 months (IQR 26-72) following implantation of PEARS. Systolic downward motion of the aortic root was significantly decreased $(12.6 \pm 3.6 \mathrm{~mm}$ pre-operation $v s .7 .9 \pm 2.9 \mathrm{~mm}$ latest followup, p<0.00001) [33] (Figures 12 and 13).
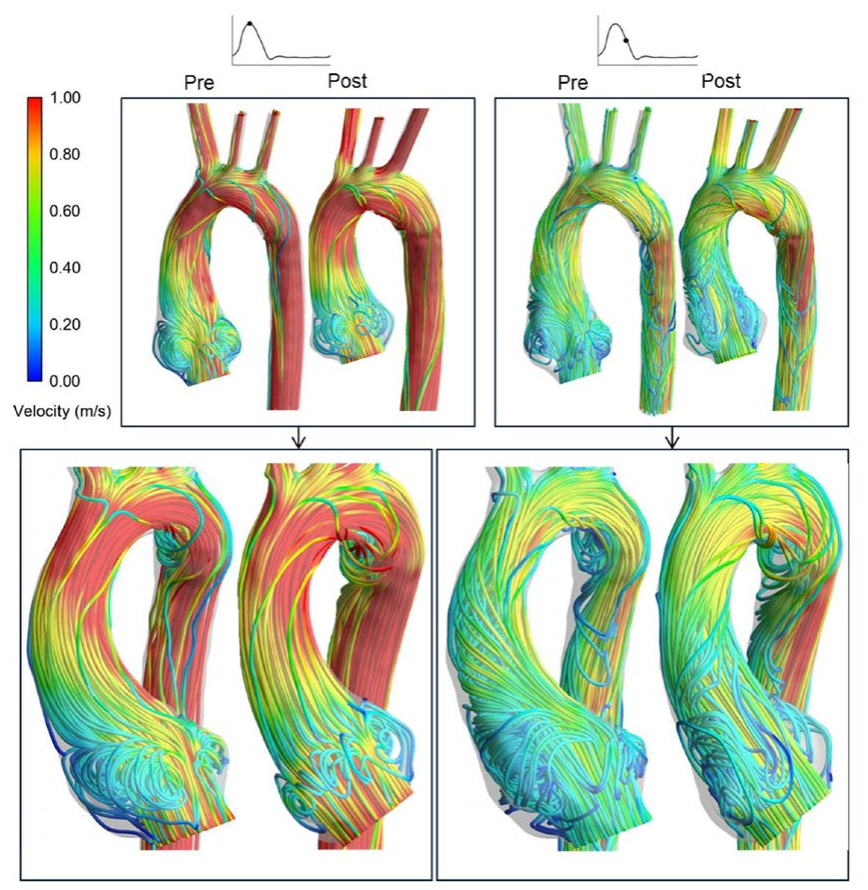

Figure 13. Pre- and post-PEARS instantaneous velocity streamlines in a Marfan patient at peak systole and mid-systolic deceleration obtained using combined CMR imaging and CFD modelling.

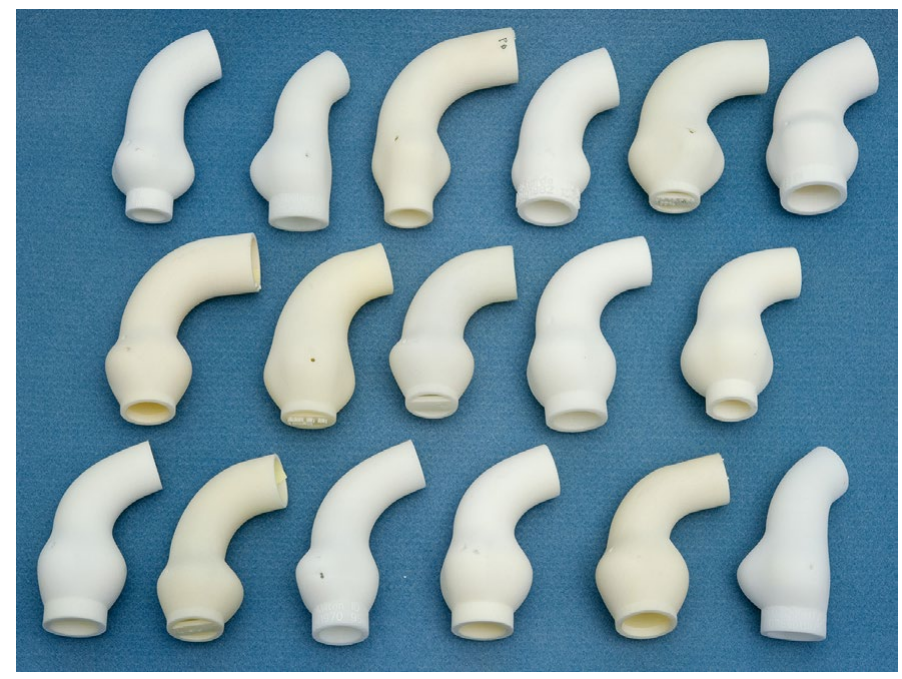

Figure 14. A series of 'copies' of individual patients' aortas showing the variation of shape and dimensions.

This work was taken a step further with engineering colleagues at Imperial College London. The biomechanical implications and haemodynamic changes associated with PEARS was investigated using combined cardiovascular magnetic resonance (CMR) imaging, finite element (FE) analyses and computational fluid dynamics (CFD). Patient-specific aortic geometries were reconstructed from preand post-PEARS CMR images of three Marfan patients. In the FE models, the wall and PEARS materials were assumed to be isotropic, incompressible and linear elastic, and a static load corresponding to the patients' pulse pressure was applied with a zero-displacement constraint at all boundaries. Results revealed peak aortic stresses and displacements before PEARS were located at the sinuses of Valsalva 
Golesworthy T (2016) An integrative approach to the Marfan aortic root between the patient, the physician and basic scientists: A case study in personalised external aortic root support (PEARS)

but following PEARS surgery, they were shifted to the aortic arch, at the interface between the supported and unsupported aorta. Nevertheless, the peak stresses found in all these models were well below the tensile strength for dilated ascending aortas. In a subsequent study, the zerodisplacement constraint at the aortic root was replaced with a systolic downward aortic root motion which revealed the PEARS significantly reduced the maximum longitudinal stress in the ascending aorta (Figure 12). The point of maximum stress and therefore greatest change was in the first few centimetres of the ascending aorta, the site at which the intimal tear of aortic dissection was most likely to occur [33].

For the CFD models, upstream flow conditions were derived from phase-contrast MR images. CFD results showed the qualitative patterns of the haemodynamics were similar pre- and post-PEARS, as seen in Figure 13, with variations in mean helicity flow indices of $-10 \%$, $35 \%$ and $20 \%$ in the post-PEARS aortas. It can be hypothesised that morphological and functional alterations of the aortic wall in the postPEARS aorta resulted in the observed changes in the haemodynamic parameters when compared with the pre-PEARS aorta. Interestingly, all values were within the reported range for normal aortas [34-36].

\section{Regulatory issues}

Introducing a new technique in surgery is now quite tightly regulated although it must be said that it is not as tightly regulated as pharmaceuticals. PEARS was initially performed under the scrutiny of Research Ethics Committee of the Royal Brompton Hospital and has subsequently been through Health Technology Approval under the British system of NICE approval [37]. It is now being considered for commissioning outside the innovating centres through a mechanism called Commissioning through Evaluation [38].

\section{Cognitive cul-de-sacs}

This experience of integrative research has been instructive in considering how we rethink problems. The nobel prize winning scientist Peter Medawar postulated that the dinosaurs were an 'end product' and might be seen as an evolutionary cul de sac. Mammals including ourselves were not a product of further evolution from the dinosaur but a step back to an earlier evolutionary branch. The eventual solution is not always reached by relentlessly solving the problems of the previous design. There were many iterative changes to the Bentall operation but the radical change was then to conserve rather than replace the aortic valve. David's operation is in its sixth version and while the operation provides excellent clinical outcomes, there are occasional deaths and problems, early and late.

An alternative is to reframe the question in the light of opportunities offered by new technology. What matters to the Marfan patient is maximising life and minimising risk and fear. The non-ablative tissue sparing solution offered by PEARS may allow very early low-risk preemptive surgery, safeguarding many Marfan patients at an earlier stage in what were precarious lives. In the future, also patients with other types of aortic disease might benefit from this technique (Figure 14).

The radical idea that resulted in PEARS was not to remove but to conserve the aortic wall. This straight away avoids all the problems related to the blood/endovascular interface. It also greatly reduces the magnitude of surgery. Added to these is the rather remarkable finding that not only does it result in a very satisfactory neo-aorta but then there is the observation that the supported aortic media is capable of healing, albeit in its fibrillin deficient state. And finally to be able to customise, individualise or personalise (call it what you will) the device to the patients is made possible by modern image acquisition, manipulation and going from image to a three dimensional product.

\section{References}

1. Coselli JS (2016) It's time to get to the root of things. J Thorac Cardiovasc Surg 151: 291-293. [Crossref]

2. Murdoch JL, Walker BA, Halpern BL, Kuzma JW, McKusick VA (1972) Life expectancy and causes of death in the Marfan syndrome. N Engl J Med 286: 804-808. [Crossref]

3. Bowen JM, Connolly HM (2014) Of Marfan's syndrome, mice, and medications. $N$ Engl J Med 371: 2127-2128. [Crossref]

4. Bentall H, De Bono A (1968) A technique for complete replacement of the ascending aorta. Thorax 23: 338-339. [Crossref]

5. Cooley D, Bloodwell R, Beall A, Hallman G, De Bakey M (1966) Surgical management of aneurysms of the ascending aorta. Surg Clin North Am 46:1033-1044.

6. Price J, Magruder JT, Young A, Grimm JC, Patel ND, et al. (2016) Long-term outcomes of aortic root operations for Marfan syndrome: A comparison of Bentall versus aortic valve-sparing procedures. $J$ Thorac Cardiovasc Surg 151:330-338.

7. Treasure T, Hasan A, Yacoub M (2011) Is there a risk in avoiding risk for younger patients with aortic valve disease. BMJ 342: d2466. [Crossref]

8. Treasure T (2010) The evolution of aortic root surgery for Marfan syndrome. Interact Cardiovasc Thorac Surg 10: 353-355. [Crossref]

9. Fagan A, Pillai R, Radley-Smith R, Yacoub M (1983) Results of new valve conserving operation for treatment of aneurysms or acute dissection of aortic root. British Heart Journal 49: 302

10. David TE, Feindel CM (1992) An aortic valve-sparing operation for patients with aortic incompetence and aneurysm of the ascending aorta. J Thorac Cardiovasc Surg 103: 617-621. [Crossref]

11. Treasure T, Golesworthy T, Pepper J, Ruiz F, Gallivan S (2011) Prophylactic surgery of the aortic root in Marfan Syndrome: reconsideration of the decision making process in the era of customised external aortic root support. Italian Journal of Vascular and Endovascular Surgery 18: 215-223.

12. Treasure T (1993) Elective replacement of the aortic root in Marfan's syndrome. $B r$ Heart J 69: 101-103. [Crossref]

13. Vahanian A, Alfieri O, Andreotti F, Antunes MJ, Baron-Esquivias G, et al. (2012) Guidelines on the management of valvular heart disease. Eur Heart J 33: 2451-2496.

14. Svensson LG, Adams DH, Bonow RO, Kouchoukos NT, Miller DC, et al. (2013) Aortic valve and ascending aorta guidelines for management and quality measures: executive summary. Ann Thorac Surg 95: 1491-1505.

15. Benedetto U, Melina G, Takkenberg JJ, Roscitano A, Angeloni E, et al. (2011) Surgica management of aortic root disease in Marfan syndrome: a systematic review and metaanalysis. Heart 97: 955-958. [Crossref]

16. Golesworthy T, Treasure T, Lamperth M, Pepper J (2006) Reducing fear and the risk of death in Marfan syndrome: a Chaucerian pilgrimage. British Journal of Cardiology 13: $267-272$.

17. Pepper J, Golesworthy T, Utley M, Chan J, Ganeshalingam S, et al. (2010) Manufacturing and placing a bespoke support for the Marfan aortic root: description of the method and technical results and status at one year for the first ten patients. Interact Cardiovasc Thorac Surg 10: 360-365.

18. Treasure T, Gallivan S, Golesworthy T, Thornton W, Lamperth M, et al. (2009) Unknown unknowns: the aorta through the looking glass. Eur J Cardiothorac Surg 35: 925-926. [Crossref]

19. Robicsek F, Thubrikar MJ (1994) Conservative operation in the management of annular dilatation and ascending aortic aneurysm. Ann Thorac Surg 57: 1672-1674. [Crossref]

20. Robicsek F, Thubrikar MJ (1994) Hemodynamic considerations regarding the mechanism and prevention of aortic dissection. Ann Thorac Surg 58: 1247-1253. [Crossref]

21. Robicsek F, Thubrikar M (1995) The mechanism and prevention of aortic dissection in Marfan syndrome; Cardiovascular Aspects of Marfan Syndrome. Darmstadt, Steinkopff, 61-70.

22. Bauer M, Grauhan O, Hetzer R (2003) Dislocated wrap after previous reduction aortoplasty causes erosion of the ascending aorta. Ann Thorac Surg 75: 583-584. 
23. Golesworthy T, Lampérth M, Mohiaddin R, Pepper J, Thornton W, et al. (2004) The Tailor of Gloucester: a jacket for the Marfan's aorta. Lancet 364: 1582. [Crossref]

24. Cohen O, Odim J, De la ZD, Ukatu C, Vyas R, et al. (2007) Long-term experience of girdling the ascending aorta with Dacron mesh as definitive treatment for aneurysmal dilation. Ann Thorac Surg 83: S780-S784

25. Hess PJ Jr, Klodell CT, Beaver TM, Martin TD (2005) The Florida sleeve: a new technique for aortic root remodeling with preservation of the aortic valve and sinuses. Ann Thorac Surg 80: 748-750. [Crossref]

26. Plonek T, Dumanski A, Obremska M, Kustrzycki W (2015) First beating-heart valvesparing aortic root repair: a "corset" technique. Ann Thorac Surg 99: 1464-1466. [Crossref]

27. Verbrugghe P, Verbeken E, Pepper J, Treasure T, Meyns B, et al. (2013) External aortic root support: a histological and mechanical study in sheep. Interact Cardiovasc Thorac Surg 17: 334-339. [Crossref]

28. Neri E, Massetti M, Tanganelli P, Capannini G, Carone E, Tripodi A, et al. (1999) Is it only a mechanical matter? Histologic modifications of the aorta underlying external banding. J Thorac Cardiovasc Surg 118: 1116-1118.

29. Pepper J, Goddard M, Mohiaddin R, Treasure T (2015) Histology of a Marfan aorta 4.5 years after personalized external aortic root support. Eur J Cardiothorac Surg 48: 502-505. [Crossref]

30. Treasure T (2013) CardioPulse: options for pre-emptive aortic root surgery for people with Marfan syndrome. Eur Heart J 34: 1947-1949. [Crossref]
31. Treasure T, Pepper J (2016) A call for expressions of interest in a comparative study of the options for pre-emptive aortic root surgery for people with Marfan syndrome. Eur $J$ Cardiothorac Surg 44:588.

32. Treasure T, Mac Rae KD (1998) Minimisation: the platinum standard for trials? Randomisation doesn't guarantee similarity of groups; minimisation does. BMJ 317 362-363. [Crossref]

33. Izgi C, Nyktari E, Alpendurada F, Bruengger AS, Pepper J, et al. (2015) Effect of personalized external aortic root support on aortic root motion and distension in Marfan syndrome patients. Int J Cardiol 197: 154-160. [Crossref]

34. Vorp DA, Schiro BJ, Ehrlich MP, Juvonen TS, Ergin MA, et al. (2003) Effect of aneurysm on the tensile strength and biomechanical behavior of the ascending thoracic aorta. Ann Thorac Surg 75: 1210-1214. [Crossref]

35. Singh SD, Xu XY, Pepper JR, Treasure T, Mohiaddin RH (2015) Biomechanica properties of the Marfan's aortic root and ascending aorta before and after personalised external aortic root support surgery. Med Eng Phys 37: 759-766.

36. Singh SD, Xu XY, Wood NB, Pepper JR, Izgi C, et al. (2016) Aortic flow patterns before and after personalised external aortic root support implantation in Marfan patients. J Biomech 49: 100-111. [Crossref]

37. Treasure T, Pepper J, Golesworthy T, Mohiaddin R, Anderson RH (2012) Externa aortic root support: NICE guidance. Heart 98: 65-68. [Crossref]

38. Dearman C, van As N, Crellin A, Slevin N, Sharma RA (2015) Surgery versus SABR for respectable non-small-cell lung cancer. Lancet Oncol 16: e373-374. [Crossref]

Copyright: (C2016 Golesworthy T. This is an open-access article distributed under the terms of the Creative Commons Attribution License, which permits unrestricted use, distribution, and reproduction in any medium, provided the original author and source are credited. 